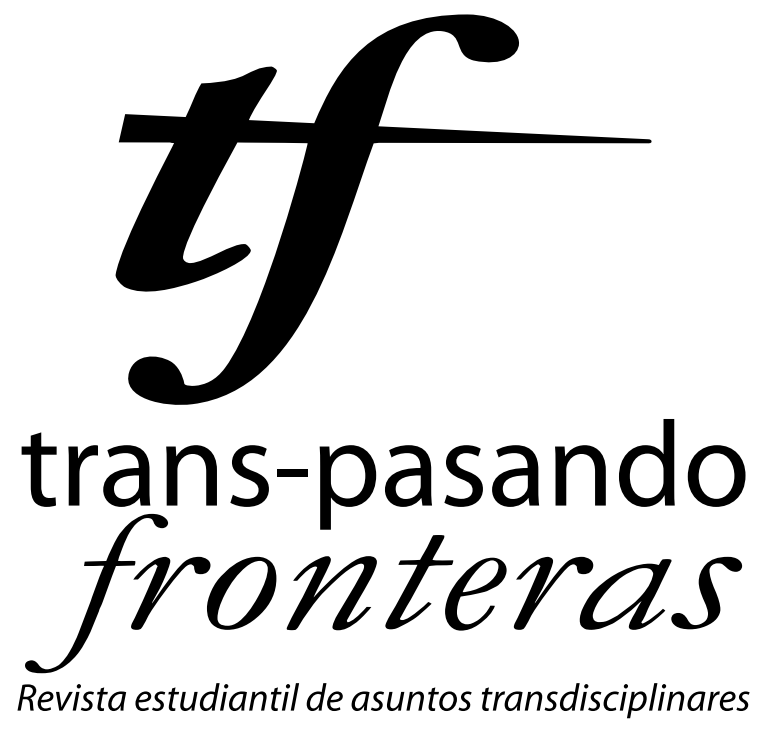

Una publicación de

Estudios

Interdisciplinarios

Jurídicos, Sociales

000 y Humanistas

ICESS

FACULTAD DE

DERECHO Y CIENCIAS

SOCIALES

然 UNIVERSIDAD 


\title{
Movimiento Estudiantil chileno de 2011 y su influencia en las reivindicaciones ciudadanas desde los márgenes regionalistas"
}

\author{
Javier Ramos Galleguillos** \\ (javramosg@gmail.com)
}

\author{
Camila Vargas $^{* * *}$ \\ (cvargasmardones@gmail.com)
}

\author{
Claudia Maluenda* \\ (claudia.maluenda.marin@gmail.com)
}

Reporte de caso recibido el 03/12/2012 y aprobado el 11/02/2013.

\begin{abstract}
हैं।
Como citar este artículo:

RAMOS GALLEGUILLOS, Javier, Camila Vargas y Claudia Maluenda (2013). "Movimiento estudiantil chileno de 2011 y su influencia en las reivindicaciones ciudadanas desde los márgenes regionalistas”. En: Trans-pasando Fronteras, Núm. 3, pp. 73-90. Cali, Colombia: Centro de Estudios Interdisciplinarios, Jurídicos, Sociales y Humanistas (CIES), Facultad de Derecho y Ciencias sociales, Universidad Icesi.
\end{abstract}

\footnotetext{
* $\quad$ Artículo presentado en el V Congreso WAPOR Latinoamérica en la mesa titulada "Protesta social y movimientos sociales". Evento organizado por la Organización Mundial de la Opinión Pública (WAPOR por sus siglas en inglés) en la Universidad Externado de Colombia en la ciudad de Bogotá del 19 al 21 de Septiembre de 2012.

** Estudiante de Periodismo de la Universidad Católica del Norte de Chile. Secretario General de la Federación de Estudiantes de la Universidad Católica del Norte. Sus áreas de interés son la política universitaria y la investigación de movimientos sociales.

*** Estudiante de Periodismo de la Universidad Católica del Norte de Chile. Consejera de la Facultad de Humanidades de la Federación de Estudiantes. Sus áreas de interés son los movimientos sociales, la investigación y política universitaria.

**** Estudiante de Periodismo de la Universidad Católica del Norte de Chile. Sus áreas de interés son la investigación, la organización y servicio social.
} 


\section{Resumen}

Uno de los conflictos sociales más significativos del año 2011 en Chile, fue el movimiento estudiantil, que en conjunto con diversos actores sociales, promovieron la consigna de una educación pública, democrática y de calidad. Bajo este argumento, la presente ponencia pretende analizar y describir de qué manera el Movimiento Estudiantil chileno iniciado en 2011, gatilla un empoderamiento ciudadano contra el régimen político y económico en favor de un Estado de Bienestar transversal a los distintos sectores sociales. Se indaga además, en las repercusiones que tuvo este Movimiento para la formulación de nuevas demandas desde los márgenes regionalistas, con el fin de interpretar el creciente descontento ciudadano y su necesidad de organización orientada a romper con la brecha de desigualdad existente en Chile.

\section{Palabras claves:}

Movimiento estudiantil, movimientos sociales, Chile.

\section{Introducción}

Las problemáticas que se generan dentro de una sociedad son variables de acuerdo a sus necesidades territoriales, ya que el entorno es el que determina al individuo; sin embargo la historia ha mostrado que la reivindicación de cualquiera de estas eventualidades compromete siempre una razón netamente económica. A su vez, la ya encausada conciencia social, toma mayor protagonismo en el conflicto, llegando a trastocar todos los sectores involucrados, y por ende, construye una unificación de fuerzas que tienen un objetivo en común.

Uno de los factores que lleva a la ciudadanía a organizarse es el acto de "abrir los ojos y despertar". Vivimos en un mundo postmoderno donde las individualidades provocadas por la globalización priman sobre los derechos básicos de las sociedades. Los medios de comunicación masivos, comandados por grandes transnacionales o por gobiernos no representativos -como parece ser el caso de Chile-, ayudan a mantener una sociedad estandarizada y poco activa políticamente. Sin embargo, ante el grado de desigualdad social existente en todo el mundo, la ciudadanía ha levantado movimientos sociales como "Los Indignados", movilizaciones ambientalistas, luchas de género, educacionales, entre otras; las que tienen en común la desesperación por ser escuchados y el cuestionamiento al sistema neoliberal y a los hegemones. Como explica Touraine (1997), actualmente la ciudadanía se debe basar en dos principios básicos, la solidaridad y la comunicación, ambas directamente relacionadas. Es necesario especificar que bajo la teoría de este autor, la comunicación debe ser usada 
para transversalizar las decisiones y que éstas, sean zanjadas por medio de la opinión pública y no de las instituciones (las cuales han perdido credibilidad por su falta de transparencia y su pésimo e imprudente actuar político contra la población). Por su parte, la solidaridad apela a la rebeldía contra la homogenización de masas y al alza del pluralismo. Un factor determinante para estas movilizaciones es la transformación que provoca el conocimiento verdadero de los hechos. Buscar información más allá de los medios tradicionales pone en estado de alerta a las personas, y con esto se vislumbra el abuso de poder que ejercen algunos grupos. Posteriormente, es necesario plantear proyecciones políticas bien organizadas, que lleguen a provocar acciones concretas contra el sistema, las instituciones y los grandes grupos económicos que manejan desde arriba este mundo que de a poco se acerca al colapso. "Ha llegado, pues, el momento de la acción, de la libertad de expresión, de la responsabilidad. Sí, ha llegado el momento de los pueblos"; de esta manera los autores del libro "Reacciona" hacen un llamado a la protesta ciudadana, para formar parte de los procesos y organizarse en pos de lograr el bienestar social necesario.

En consecuencia, la idea de bienestar ha polarizado a sus actores, dando paso al debate que muchas veces las clases dominantes han apaciguado para proteger la integridad de un Estado, institución u organismo encargado de velar por la prosperidad de cierto territorio. Precisamente en Chile, se han desencadenado más de seis reivindicaciones regionales y de carácter nacional durante los años 2011 y 2012 , basado en el alero de la igualdad y el reclamo contra un sistema neoliberal que, en su afán materialista, aletarga una sociedad desprovista de educación cívica.

El movimiento estudiantil es una de las movilizaciones más extensas y multitudinarias que ha experimentado el país, con la consigna de una educación pública y de calidad, transversaliza las demandas para ya no ser sólo una protesta de estudiantes, sino que guarda relación con el concepto de base social en el cual estamos inmersos. Para continuar con esta correspondencia la educación en Chile se ha privatizado desde hace tres décadas, consagrando un aumento sustancial del costo en materia financiera para quienes adquieran este servicio, valor impuesto no representado en las aulas y que se avista hoy como un privilegio, particularmente en instituciones privadas que segmentan el aprendizaje cuantificando la calidad de enseñanza en proporción a la vida material de las familias chilenas, y en donde los sectores más bajos no pueden 
acceder, relegando la educación entonces a entidades municipales que no cumplen con los estándares mínimos de calidad. Esta coyuntura social dio paso a las reivindicaciones que apuntan a cambios estructurales y que buscan aunar fuerzas, tal como lo explica el sociólogo Manuel Antonio Garretón.

\begin{abstract}
En las transiciones los movimientos sociales tienen una dimensión de historicidad que es particular, diferente, por ejemplo el movimiento obrero o un movimiento de clase o de género, y es que apunta al cambio de régimen. Ése es el sentido de historicidad de los movimientos sociales en periodos de transición democrática y que redefine o reelabora los otros sentidos de los movimientos sociales.
\end{abstract}

\title{
Algunas ideas contextualizadoras
}

Para contextualizar esta investigación, es pertinente identificar los distintos ejes sociales, históricos y políticos que determinan la actual identidad nacional sobre la educación y otras demandas sociales; de qué manera lo abordan las políticas públicas, y cómo la ciudadanía comienza a adquirir un rol fiscalizador y participativo en pos de cambios eficientes por parte de la clase política para las personas. Sin embargo, por el pasado mercantilista de Chile es necesario hacer un análisis para comprender las causas y consecuencias del actual clima de lucha social en el país, con el fin comprobar que en este juego de poderes no existen coincidencias.

\section{Historia y actualidad}

Desde la matanza de la Escuela de Santa María de Iquique el 21 de Diciembre de 1907 hasta la movilización de Aysén, las reivindicaciones han tenido lugar en la historia de este largo país y su oscilante tejido social. De esta manera Gabriel Salazar - connotado sociólogo e historiador chileno- destaca que, a nivel histórico, "la memoria debe ser revisada e intervenida a fin de reconstruir el capital social que se ha perdido" (Cortéz Lutz, 2012) . Pues, contextualizando, se muestra la necesidad de retroalimentar la historia política de Chile para entender realmente el origen del problema e interpretar cómo el movimiento estudiantil supo empoderarse de la opinión pública exigiendo a través de esto, la salida de lo único que ha permanecido vivo durante los últimos cien años y que ha reducido al Estado a un simple concepto: el Mercado. 
Respecto a lo anterior, es necesario declarar al Mercado como la constante a lo largo de muchos años, pues hasta la actualidad la doctrina del economista Milton Friedman transformó la proyección chilena de un Estado de Bienestar y benefactor social, al de una sociedad donde la mercantilización de necesidades abarcó desde los recursos naturales, hasta la salud y, por supuesto, la educación. La incursión calculadora de Friedman en la dictadura militar queda explícita en la carta que le envió a Pinochet el 21 de abril de 1975, donde afirma que "en la práctica, disminuir el gasto público es, por lejos, la manera más conveniente para reducir el déficit fiscal ya que, simultáneamente, contribuye al fortalecimiento del sector privado y, por ende, a sentar las bases de un saludable crecimiento económico" (Piñera J., 2006); predicando un discurso que en definitiva motivaría a la concesión de gran parte de los servicios públicos del país.

Años antes, para el ex Presidente de la República, José Manuel Balmaceda, la educación era el único método que el Estado podía entregar para asegurar efectivamente la movilidad social y a la vez contribuir al progreso del país, por lo cual sus políticas para revitalizar la educación pública y la industria nacional fueron una de las principales amenazas para los grupos de poder detrás de la pujante economía industrial transnacional de la época salitrera.

En definitiva, Balmaceda terminó siendo martirizado por un Golpe de Estado, acallando con él los afanes de un fortalecimiento necesario de la educación. Sin embargo, este sería sólo el comienzo de una seguidilla de eventos históricos que marcarían al conjunto de la sociedad chilena.

Tanto lo sucedido con Balmaceda, como el alzamiento militar contra Salvador Allende, convergen en otra constante de carácter político que refuerza la tendencia económica neoliberal de Chile; esta es la Constitución Política de 1980 , discutida y promulgada en medio de la convulsión social propia de la Dictadura.

Este es el punto donde los tres ejes antes mencionados confluyen y nos ayudan a dilucidar las razones por las cuales Chile es uno de los países más desiguales de la OCDE a pesar de su pujante y alabada economía. En este sentido, la combinación de neoliberalismo y política aplicada a la sociedad de dependencia, necesariamente presupone una división de clases entre los que poseen más y los que poseen menos, provocando con 
esto una elitización de los servicios según los ingresos del consumidor; en el caso de la educación, la poca intervención del Estado ha limitado la buena enseñanza a quienes tengan el dinero para comprarla, o para quienes se endeudan. Reflejo de esto son las cifras que presentó María Olivia Monckeberg, Premio Nacional de Periodismo 2009, en su investigación titulada "El negocio de las Universidades en Chile". En él devela la gran segmentación que causa la educación de mercado, reservando la oportunidad de estudiar a "consumidores" con mayor poder adquisitivo. Monckeberg ejemplifica y denuncia cómo la Universidad de Los Andes (institución de educación privada y perteneciente al Opus Dei) sólo recibe un 2\% de estudiantes provenientes de educación municipal, un 7\% de educación particular subvencionada (también entendible como mixta entre sostenedores y fondos estatales), y un escalofriante pero real $89,5 \%$ de estudiantes procedentes de colegios particulares pagados. Abrumadoras cifras que se agudizan al notar en sus llamativas publicidades el respaldo de la Comisión Nacional de Acreditación, mostrando las nociones de formación y enseñanza que pretenden instaurar los empresarios de la educación; sin duda un negocio rentable en este país.

Otra arista del conflicto educacional es el lucro, el cual es una de las razones centrales de la movilización. El acto de lucrar se puede definir como la ganancia adquirida como consecuencia del incumplimiento de una obligación, por la cual normalmente el causante del daño, o sea la empresa educativa, debe indemnizar a la otra parte, o sea al cliente-estudiante. Es necesario aclarar este concepto para lograr el análisis de la gran problemática existente en el país. Siendo parte de la Constitución de la República de Chile, la Ley General de Educación (Ley 18.962), Artículo 34, indica que las instituciones universitarias que no se formen por decreto deberán hacerlo "conforme a los procedimientos establecidos en esta ley, y serán siempre corporaciones de derecho privado, sin fines de lucro".

Es aquí donde nace la indignación de miles, pues se ve cómo el marco legal relata de manera prodigiosa una regulación eficiente para supervigilar a los sostenedores económicos, y de esta manera dar una "libertad" de elección a los consumidores. No obstante, toda intención de cumplir el no lucro de centros educacionales queda en nada más que palabras, pues sólo en el 2011, se puso en marcha la creación de una Superintendencia de la Educación para intentar regular este verdadero mercado de educación.

En este sentido, el delito de lucrar pasó por alto las leyes educacionales durante 
décadas. No obstante, este año comenzó la formación de la comisión investigadora de la Cámara de Diputados, la cual presentó un informe donde afirman que "el sistema de educación chileno creado bajo el gobierno militar ha forzado el desapego del Estado de las universidades públicas". De esta manera se ha beneficiado estratégicamente a las entidades privadas, generando una pelea sin cuartel. Un ejemplo de esto es que "la universidad más poblada de Chile es privada. El fondo estadounidense Laureate International Universities posee en su cartera, entre otras, a las casas Andrés Bello, De las Américas y Viña del Mar, y juntas superan los 50.000 alumnos".

En el informe se evidencian las grandes irregularidades que existen con la educación universitaria, debido a los conflictos de interés y exagerados aranceles en las casa de estudio. Esto se ve reflejado en los datos que entrega el economista chileno Marcel Claude: "el Banco Mundial señaló que cuando un estudiante se gradúa y sale al mercado laboral carga con un endeudamiento equivalente al $174 \%$ de su sueldo anual. Eso es una locura. Aunque un estudiante trabaje un año completo, todo el ingreso que gana tendrá que dejarlo en el banco. Se estima que cada estudiante se gradúa con una deuda promedio de 40 mil dólares".

Claramente este proceso, herencia del gobierno de Ricardo Lagos, fomenta el endeudamiento familiar con la formación abrupta de opciones crediticias como el Crédito Corfo. Esta máquina de endeudamiento dejó de existir este año y generó millonarias deudas a las familias de los "beneficiarios", las que deberán pagar en un plazo de 3 años la cantidad de dinero que hayan gastado en sus estudios, con un interés del $7 \%$ u $8 \%$; una pintoresca y muy chilena manera de ocultar bajo la palabra "fomento" un verdadero engaño.

$\mathrm{Al}$ igual que una olla de presión, los estudiantes que en el 2006 iniciaron su lucha contra el modelo educacional, embistieron el 2011 con críticas y propuestas apuntadas a cambios estructurales nunca antes percibidas desde un movimiento estudiantil. El método; peticiones coherentes y aceptadas por la población, marchas caracterizadas por la cultura e imaginación de los manifestantes, tomas de universidades y liceos durante más de siete meses de movilización, además de la utilización de las redes sociales para potenciar la organización. El movimiento estudiantil se lleno de vanguardia en esta nueva forma de protestar.

Sin embargo, la represión proveniente del gobierno y el Ministerio del Interior, comandado -hasta ahora- por Rodrigo Hinzpeter, intentó silenciar a los manifestantes uti- 
lizando carros lanza agua, bombas lacrimógenas, tanquetas anti barricadas, detenciones fuera del marco legal, detenidos políticos, una cantidad desmesurada de Fuerzas Especiales (FF.EE.) y carabineros, como respuesta frente a las demandas estudiantiles, fundando así, una radicalización en las medidas de lucha, tanto política como física de los estudiantes contra las fuerzas de orden público. Era clara entonces, la necesidad de confrontar mediante la violencia toda movilización social, pues la fuerza con que golpeó la represión al movimiento estudiantil dejaría su huella.

El tiempo dio la cuenta de semejante violencia; el 25 de agosto de 2011 fue asesinado un joven de 16 años, Manuel Gutiérrez Reinoso, en una jornada de paralización organizada por la Central Unitaria de Trabajadores (CUT) y acompañada por los estudiantes. Su asesino, fue el sargento de Carabineros Miguel Millacura Cárcamo, quien hasta hoy no ha sido procesado por este macabro hecho. La lucha cobraba su primera víctima en el año.

\section{La Ley "Hinzpeter"}

La visión panóptica de las clases dominantes está claramente expresada en el actuar represivo del gobierno frente a las movilizaciones sociales, según Foucault esta es una de las técnicas hegemónicas para garantizar el orden y repeler a las masas que se intenten sublevar ante el sistema

Cada cual, en su lugar, está bien encerrado en una celda en la que es visto de frente por el vigilante; pero los muros laterales le impiden entrar en contacto con sus compañeros. Es visto, pero él no ve; objeto de una información, jamás sujeto en una comunicación. (2002; 159).

Es bajo este tenso contexto entre el gobierno y los manifestantes que nace el Proyecto de Ley de Resguardo del Orden Público, popularmente conocida como la "Ley Hinzpeter".

La actual Constitución declara la existencia del "derecho a reunirse pacificamente sin permiso previo..." (Art. 19, no 13), sin embargo el Decreto Supremo 1.086 dictado en 1983 se contradice con esto explicitando que la autoridad puede prohibir y regular las manifestaciones que ellos consideren inconvenientes. Nos encontramos frente a una incoherencia legal abismante que se puede definir anticonstitucional.

Tomando en cuenta los antecedentes expuestos podemos asegurar que el Estado chi- 
leno busca callar el despertar fulminante que ha movilizado a la ciudadanía, por lo cual el Ministerio del Interior impulsaría la promulgación de esta ley que, según el abogado de la defensoría popular de Santiago, Rodrigo Román desvirtúa el “derecho penal como herramienta de control social". En su construcción, el proyecto contempla una serie de parámetros para amparar legalmente ciertos métodos clásicos de la dictadura. A modo de ejemplo, el artículo 269 de esta normativa propone que:

Serán castigados con la pena de presidio menor en su grado medio quienes participen en desórdenes o cualquier otro acto de fuerza o violencia que importen la realización de paralizar algún servicio público, invadir, ocupar o saquear establecimientos privados o públicos, actuar a rostro cubierto (encapuchados), impedir la libre circulación de las personas.

Acompañando a este canasto de medidas, el proyecto además contempla entregar a las fuerzas de orden la facultad de incautar documentos o grabaciones de personas que estén presentes mientras transcurren estos actos. A vivas luces, una manera explícita y legal para devolver a la gente consciente al letargo que tan bien preparó Augusto Pinochet y que está en directa relación con la visión panóptica de la sociedad. Como toda lógica de control social, se intenta gobernar literalmente con un garrote en la mano.

Ante el panorama analizado, se muestra evidente y preocupante cómo la identidad de los habitantes de Chile ha sido fuertemente remecida a lo largo de su historia, desembocando en el malestar generalizado de la actual ciudadanía; muy por sobre la indiferencia que se había mostrado en los últimos 20 años de "democracia".

\section{De lo particular a lo general: de la lucha sectorial a la movilización social}

La lucha social y reivindicadora que ha venido forjando el país, cobra sentido sólo cuando los ánimos de cambio en las bases se encuentran por sobre el afán oportunista de la actual clase política. Es ahí donde romperemos la pared burocrática y desigual que la burguesía y su sociedad de mercado mancharon el pensar, el soñar y el vivir de toda una generación engañada en la representatividad. Esto fue quizás, lo que hizo estallar el cambio de conciencia social y poder organizativo bajo una especie de constructivismo colectivo (Javaloy, Rodríguez y Espelt, 2001) que se 
observa hoy en las regiones marginadas de Chile.

En una investigación referente a los movimientos sociales y evolución política, el sociólogo Alberto Mayol (2012) identifica el acto de la liberación del malestar social como una "salvación" en pos del bienestar social, en la cual las injusticias, la expropiación de tierras e incluso la mala distribución de los recursos son la piedra angular para constituir un descontento generalizado.

Es en esta instancia de malestar cuando el individuo ve vulnerado sus derechos y experimenta la frustración, al no poder conseguir aquella salvación intelectual, económica o social que persiguen los movimientos sociales. Con esto se plasma tangible el por qué de toda reivindicación; desencadenando la identificación de la superestructura y el cuestionamiento constante a su hegemonía.

Sin embargo, los puntos geográficos trascendentales de la economía nacional identificaron y denunciaron esta supremacía de la superestructura, emancipando la lucha particular de la educación, salud, trabajo y transporte, en una demanda general que representa las necesidades de las personas partiendo desde la base democrática. Calama es uno de esos frentes que ha levantado una demanda ciudadana concreta.

\section{Linea de Tiempo de la lucha social de Calama y sus constantes}

Desde el periodo del auge salitrero en el siglo XIX, las promesas de industrialización del cobre y el actual panorama de licitaciones de Litio, el Estado de Chile nunca ha conseguido explotar sus recursos naturales prescindiendo a la empresa extranjera de tan suculento negocio. Como afirmó Eduardo Galeano (1971) en la época pre-dictadura: "la nacionalización pondrá fin a un estado de cosas que se había hecho insoportable para el país, y evitará que se repita, con el cobre, la experiencia de saqueo y caída en el vacio que sufrió Chile en el ciclo del salitre". De esta manera, queda explicitado el verdadero colonialismo empresarial que consolida lo que Milton Friedman aplaudiría como la mezcla perfecta entre un Estado pasivo y escasamente regulador a la merced de un Mercado completamente autorregulado, alimentándose de la inequidad e injusticia que genera el modelo Neoliberal en la actualidad. En estas últimas palabras es donde se comienza a engendrar el malestar de los ciudadanos de Calama; la inequidad y la injusticia, los cuales emanan de la clara marginación de la zona minera y pulmón económico de Chile. 
El contexto que se vive en Calama es paradójico, pues el fantasma del centralismo que tanto se remarcó en la dictadura militar y su Constitución Política fuertemente generosa y permisiva con el capital extranjero, muestran ahora su cara más oscura con un gobierno de corte derechista, en una época de convulsión social activa. Esta efervescencia mezclada con las negativas del Gobierno de turno respecto a mejoras salariales, cambios estructurales y reformas tributarias fuerte, condimentan lo que, a vivas luces, es la aproximación de un conflicto social que sigue la lógica del Movimiento Estudiantil 2011, el Movimiento Ciudadano de Aysén y otros frentes de lucha; una organización social constituida por una base consciente y fuertemente organizada.

\section{Calama y sus particularidades}

El caso peculiar de Calama, es una atractiva muestra de lo que pese a años de marginación y marcada concienciación convergen en un empoderamiento ciudadano respaldado por las bases, y en cuya formación se refleja el trabajo ciudadano que desde sus comienzos -en el año 2009- se concretó bajo el nombre de "Asamblea ciudadana de Calama", congregando como su principal demanda la restitución de la Ley 11.828 , para que el $5 \%$ de los excedentes del cobre se concentre en la ciudad y a su vez sea administrado por el municipio.

Bajo consignas como "¿Qué sería de Chile sin Calama?, o "Producimos cobre, seguimos pobres", el movimiento en esta zona no ha estado ausente de la opresión que se radicaliza bajo el alero del orden público, las represiones por parte del Grupo de Operaciones Policiales Especiales, han confirmado nuevamente la jugada política del actual gobierno. Entre la que destaca la detención del Alcalde de la ciudad, Esteban Velásquez, en el Paro Comunal del 29 de agosto del año pasado, mientras que la adhesión a este paro "superaba las 20 mil personas en la calle, acompañados de una caravana de tres mil automóviles, más la paralización del 100\% del transporte, el $80 \%$ del comercio y un $60 \%$ de los servicios públicos". Por supuesto el nivel organizacional siguió la lógica histórica a la cual obedecen los movimientos sociales, logrando entre el 2011 y 2012 una fuerte unión entre los sectores públicos, sindicatos de trabajadores y estudiantes. Ante esto, las conclusiones de José Mardones, presidente de la Central Unitaria de Trabajadores (CUT) en Calama, confirman 
este vínculo que genera como hemos mencionado anteriormente, una conciencia social que se fortalece con los distintos sectores y logran adquirir mayor relevancia para hacer más efectiva la búsqueda de sus demandas.

\begin{abstract}
Los estudiantes se empiezan a incorporar con una participación muy fuerte en las manifestaciones del movimiento, en los paros del 29 de julio y 29 de agosto de 2011, y empezamos a generar esa unión de los trabajadores y los estudiantes. Hoy claramente estamos trabajando en conjunto con ellos para poder en definitiva incorporar demandas no tan solo de los estudiantes sino también de los trabajadores (Mardones; 2012).
\end{abstract}

La constante que muestran los movimientos actuales provienen de la misma raíz; la problemática económica. Es por esto que las causales para semejante malestar están a la vista de todos sus habitantes, pues a la luz de las cifras, resulta incomprensible como la ciudad que alberga a gran parte de los trabajadores que aportaron a las arcas fiscales, solo en 2011 una suma de US\$ 5.301, sea la $16^{\circ}$ ciudad con peor calidad de vida en todo Chile. Esta triste realidad se vuelve más aterradora y cobra mayor sentido con las cifras de la OCDE que sitúa a Chile como uno de los países con peor distribución de este sondeo.

Todos estos números y cifras, no son más que el sustento empírico de una realidad que es sabida desde hace muchos años, y por la cual han muerto cientos en busca de alguna solución. Esta realidad alude a que las clases sociales en Chile están lejos de acabarse, y las desigualdades que se dan en lugares tan significativos como Calama, predice el nivel de indignación que existe en gran parte del país que, en cuanto a producción, no son nada para los grupos de poder económicos. Sin embargo, desde los universitarios indignados de la Ley Marco en 1997 -que hoy son trabajadores- hasta los pingüinos de 2006 -que hoy son universitarios- conforman una generación que ha vivido la maquinaria estructurada en la Constitución de Augusto Pinochet, germinando un malestar que viene acumulado desde el miedo de la dictadura hasta el empoderamiento social que se avista en lo que parece ser el despertar de una ciudadanía dormida por el engaño de la falsa democracia de 1989.

\title{
Aysén, otro punto de marginación
}

La comuna de Aysén perteneciente a la región Carlos Ibañez del Campo, es una localidad 
ubicada en el extremo sur de Chile, y en cuyo seno alberga a campesinos, pescadores y pobladores, acompañado por supuesto, de las autoridades de gobierno regional, este territorio es conocido por su hermosa Patagonia conectada con Argentina, y por ser uno de los últimos territorios en caer bajo la colonización europea.

Al igual que gran parte de las zonas extremas del longitudinal país, la marginación parece ser un problema social permanente y transversal a cualquier color político, así nos señala Claudia Torres, diseñadora gráfica, locutora de Radio Santa María y parte del Movimiento Social por Aysén. Esta organización social vió nacer el 13 de Febrero del 2012, una lucha que cerraría un poblado estratégico a nivel nacional, y en cuya radicalización los pescadores de la zona austral se tomaron el aeródromo de "Melinka" para manifestar su rechazo absoluto a la nueva "Ley de Pesca" que encabeza el Ministro de Economía, Pablo Longueira; el Movimiento de Aysén había comenzado.

Ante una nueva revuelta, el Gobierno y su Ministerio del Interior ordenaron la intervención de Fuerzas Especiales, reprimiendo con las ya conocidas bombas lacrimógenas, perdigones de acero y goma, carros lanza agua y carros lanza gases a los manifestantes. Cómo se ha demostrado a lo largo de nuestra investigación esta estrategia surge cada vez que existe algún tipo de alzamiento popular, lo que deja en evidencia el descontrol institucional que se produce cuando el pueblo lucha por causas justas. De esta manera se ve manifestado el efecto que anteriormente nombramos.

La indignación se puede discutir con los amigos... Alegando en la casa te indignas, empiezas a tener ese malestar, ese sentimiento que te atropella el corazón y puedes quedar hasta ahi. Sin embargo, si te fijas uno ve en los medios tradicionales que todos los días hay una barricada, un piquete contra el sistema de transporte público, manifestaciones por las altas tarifas telefónicas; o sea la gente pasó de la indignación, que la tenemos hace mucho tiempo, a la acción.

En este contexto, sólo fue cosa de días para que dicho sentimiento se apoderara de otros sectores sociales.

A los pescadores de Aysén - prácticamente en su totalidad artesanales- se sumaría el sector del transporte, los estudiantes, dueñas de casa, juntas vecinales, agrupaciones ambientalistas como "Patagonia sin Represas", la CUT, entre otros. La idea era evidente; unificar la 
lucha y demandas de los distintos actores afectados en una de las regiones más extremas, en donde el costo de vida y el apego a su tierra identifica a los habitantes de la zona.

La forma de organización de esta movilización fue en base a asambleas ciudadanas, cuya principal y más sorprendente característica, fue su alejamiento de los partidos políticos, generando una lista de 11 demandas. Peticiones que van desde la eliminación del impuesto a los combustibles, mejoras en el sector de salud pública, equidad laboral, participación ciudadana vinculante frente a evaluaciones de megaproyectos como "Hidroaysén” y "Energía Austral”, una universidad pública regional a la par con los estándares demandados por el movimiento estudiantil, regionalización y administración provincial de los recursos naturales, mejoramiento de la calidad de vida, y mejoras en el sistema de transporte y vivienda; en carreteras y subsidios especiales, respectivamente.

Transcurrida la movilización de la región de Aysén, la encuesta pública nacional encargada por la empresa ADIMARK manifestó la gran crisis de representatividad que vive el país; el gobierno de Sebastián Piñera obtuvo un 22\% de aprobación y un 79\% de desaprobación de la ciudadanía. Es necesario destacar que es la segunda evaluación más débil en lo que va del mandato del Presidente Sebastián Piñera (la primera fue durante el movimiento estudiantil de 2011). Según esta misma encuesta las demandas presentadas por Aysén fueron acogidas por la ciudadanía con una aprobación del $82 \%$ terminando de deslegitimizar el trabajo del gobierno oficialista.

La intención de diálogo por parte de los representantes del gobierno, fue aceptada por el movimiento social por Aysén, formando así, una mesa de diálogo, que se vio truncada con la aplicación de la Ley de Seguridad del Estado al interponer una querella contra 22 ayseninos, quienes se vieron en la necesidad de amprarse en la clandestinidad. Es necesario destacar que esta ley fue promulgada en 1975, durante los primeros alzamientos contra la Dictadura militar y solo puede ocuparse mediante una denuncia impuesta por el Ministro del Interior.

A fines de marzo, y luego de que el gobierno depusiera la querella, el movimiento logró acuerdo en algunos de los puntos, entre los más importantes se acordó un beneficio tributario, estableciendo una zona franca en la región de Aysén, lo que trae como consecuencia una baja de impuestos a los productos que llegan a la zona, además de 
la constitución de beneficios educacionales a los habitantes de la región. Sin embargo este acuerdo propone la instauración de becas, hecho que se contrapone con las demandas nacionales presentadas por la Confech.

No obstante, la frágil y preocupante memoria de la clase política deja en ascuas los supuestos logros que, apelando a la historia, muchas veces cuesta concretar en el país. Manuel Antonio Garretón logra teorizar esta idea desde un punto de vista de la transicional desde el término de la dictadura:

Así, pese a las reformas introducidas en los veinte años de régimen post dictatorial, no se puede hablar de una democracia o transición, como gustan hacerlo todos los rankings comparativos que ponen a Chile en los primeros lugares junto a Uruguay en el contexto latinoamericano; insisto en que la democratización política chilena tuvo la forma de transiciones, y esa forma y momentos, una vez terminados, dieron como resultado una democracia incompleta (2011)

\section{Conclusiones (no definitivas acerca de la problemática)}

Chile es un país que, dada su historia, determina frentes de lucha social muy impermeables y cerrados a las políticas provenientes de la gente común y corriente. En este sentido, y bajo la división de clases que existe en la sociedad, los chilenos delegaron el poder popular en manos de una democracia representativa que cada vez decepciona más y pone en duda estos puntos. Sin duda hoy, la democracia y el bienestar social son palabras totalmente subjetivas dependiendo de quién y en qué contexto se aplique.

Es complejo determinar conclusiones definitivas, sobre todo cuando se muestra un panorama tan oscilante como es el caso de las luchas sociales en Chile. Si bien se logran detectar los vértices que componen este comportamiento social de la reivindicación, estas tienden a ser muy maleables, ya que la conciencia social chilena ha sido bastante moldeada dependiendo de cada periodo histórico.

A lo largo de la historia, la clase política y su poder legislativo representado en el Congreso, se han establecido en el encause de las políticas públicas de Chile, marginando al ciudadano sólo a un rol de consumidor de bienes, relegando el poder a esta clase política que fue tomando cada vez más soberanía con base al conformismo típico del posmodernismo.

Este punto marca una de las conclusiones de esta investigación; como la pacien- 
cia y la frustraciones de no poder participar en la construcción de un país jugaron un rol fundamental en el empoderamiento ciudadano que se ve actualmente, y de qué manera estos sentimientos se apoderaron de grandes grupos de personas que buscan hasta hoy mejorar la distribución de recursos y lograr mayor equidad para quienes componemos el motor productor de Chile.

Debido a esto, es preciso destacar las constantes en común que poseen cada uno de los movimientos existentes en los márgenes regionalistas. Tales como el mercado, el monopólico poder político, la represión e incluso el poco conocimiento sobre educación cívica, son los hechos que explican un empoderamiento de estas dimensiones

El letargo en el cual estaba dormida la sociedad chilena no es un mero intento de exagerar los daños que causó la dictadura en la gente, pues los daños causados al mediano y largo plazo fueron quizás el mayor triunfo que tuvo el Golpe de Estado. No obstante, esa conciencia casi molida y rebajada en importancia, toma poder sólo cuando la gente entiende que pertenece a una base que sujeta una sociedad piramidal cuya cúspide y sus privilegios han sido reservados para quienes dominen las constantes antes mencionadas. Fuera de toda metáfora y mención poética sobre los hechos, a nivel social, realmente existió un despertar jamás visto por las generaciones posdictadura.

En el presente no intentamos proponer una mirada responsable de la evolución de los movimientos sociales, otros libros se encargan de eso. Acá redactamos de manera subjetiva la visión de vida y ambiciones a las cuales aspiran las personas, pues nos parece completamente irrisorio tolerar y aceptar semejante ambiente de inequidad social.

Más que enaltecer cierta clase social, partido político o grupo económico, se pretende plasmar la necesidad urgente de determinar un Bien Común cuerdo y justo para todos los actores sociales presentes, con el fin de recuperar la humanidad perdida de la democracia y, en conclusión, devolver el poder de decisión a la única constante marginada, golpeada, demonizada y asesinada de toda esta ecuación: el pueblo.

Sólo falta humanizar la política y agitar el atrevimiento hacia quienes nos rebajaron a semejante situación de subordinación.

Hay que tener una gran dosis de humanidad, una gran dosis de sentido de la justicia y de la verdad, para no caer en extremos dogmáticos, en escolasticismos fríos, en aislamiento de las masas. Todos los días hay que luchar porque ese 
amor a la humanidad viviente se transforme en hechos concretos, en actos que sirvan de ejemplo...de movilización (1975). Ernesto "Che" Guevara

\section{Bibliografía}

ADIMARK (2012). Encuesta: evaluación gestión del gobierno. Marzo. Santiago, Chile ÁVILA, C (2011). Chile: el país más desigual de la OCDE. Radio Universidad de Chile. Consulta realizada desde: http://radio.uchile.cl/noticias/132792/

CORTEZ, G (2012). Historia del mundo, visión crítica parte I. Consulta realizada desde: http://www.guillermocorteslutz.blogspot.com/

FOUCAULT, M (2002). Vigilar y castigar, el nacimiento de una prisión. ( $1^{\mathrm{a}}$ ed.) Buenos Aires, Argentina: Ediciones Siglo XXI

GALEANO, Eduardo (1971). Las venas abiertas de América Latina. (1 $1^{\mathrm{a}}$ ed.). Argentina. Siglo XXI editores

GARRETÓN, Manuel (2011). "Movilizaciones y movimientos social en la democratización política chilena”. En: La sociedad española en la transición, los movimientos sociales en el proceso democratizador, pp. 107-119. España: Siglo XXI editores

GUEVARA, E. (1975). El Socialismo y el Hombre Nuevo. Editorial Siglo Veintiuno

JAVALOY, F.; Rodríguez, A; Espelt, E. (2001). Comportamientos colectivos y movimientos sociales. España. Editorial Prentice Hall

RAFAEL MAYOL, Alberto (2012). No al lucro. De la crisis del modelo a la nueva era politica. Chile. Editorial Debate

MONCKEBERG, M. (2007). El negocio de las universidades en Chile. (2 .ed.) Chile. Editorial MONCKEBERG Debolsillo

SAMPEDRO, J., Mayor, F., Garzón, B., Torres, J., Martínez, A., Escolar, I., et.all (2011). Reacciona, 10 razones por las que debes actuar frente a la crisis económica, política y social. España. Editorial Aguilera

TOURAINE, A (1997). ¿Podremos vivir juntos? Iguales y diferentes. Madrid, España. PPC Editorial

\section{Fuentes normativas}

Constitución Política de la República de Chile promulgada el año 1980, $13^{\circ}$ edición 
Decreto Supremo № 1086. Ministerio del Interior. 1983, 16 de septiembre

Proyecto de Ley $\mathrm{N}^{\circ}$ 359. Cámara de Diputados de Chile, Viña del Mar. 2011, 04 de Octubre

\section{Entrevistas}

RAMOS, G (Entrevistador). Torres, C (Entrevistada) (2012). La movilización ciudadana de la región de Aysén y su acercamiento al movimiento estudiantil del año 2011 [Transcripción de entrevista]

VARGAS, C (Entrevistadora); Mardones, J (Entrevistado) (2012). Asamblea ciudadana de Calama, una reivindicación social que une a estudiantes y trabajadores [Transcripción Entrevista]

MALUENDA, C (Entrevistadora); Aguilera, V (Entrevistado) (2012). Movimientos social de Magallanes y Aysén [Transcripción Entrevista]

\section{Linkografia}

COMISIÓN INVESTIGADORA (2012). Informe de la comisión investigadora sobre el funcionamiento de la educación superior. Consulta realizada el 18 de junio de 2012, desde: https://docs.google.com/file/d/0B04dcvVW6kXQX2oyMDZ3WkkxSjQ/edit

EL MOSTRADOR (2011, 05 de Agosto). Marcel Claude: "Tenemos la educación universitaria más cara del mundo". En: El Mostrador. Consulta realizada desde: http:// www.elmostrador.cl

Encuesta de evaluación y gestión del gobierno, informe mensual de marzo 2012. Consulta realizada desde: http://www.elmostrador.cl/media/2012/04/Encuesta-Adimark-Marzo-2012.pdf

Open Source Professional Portal Sistem, cuestionan excedentes de Codelco al tercer trimestre. Consulta realizada desde: http://www.defensadelcobre.info/modules.php?nam $\mathrm{e}=$ News\&file $=$ print\&sid $=13431$

PIÑERA, J. (2006). Milton Friedman y sus recomendaciones a Chile. Consulta realizada desde: http://www.elcato.org/milton-friedman-y-sus-recomendaciones-chile

Universidad de Buenos Aires, (2011), Sintesis informativa; Chile: detalles de un sistema universitario que enoja estudiantes. Consulta realizada desde: http://www.uba.ar/ comunicacion/detalle_nota.php?id=3719 